\title{
Esophageal Necrotic Lesion
}

National Cancer Institute

\section{Source}

National Cancer Institute. Esophageal Necrotic Lesion. NCI Thesaurus. Code C78278.

A necrotic process involving the esophageal wall. 